\title{
JSLHR
}

\section{Article \\ Past Tense Production by English Second Language Learners With and Without Language Impairment}

\author{
Elma Blom ${ }^{a}$ and Johanne Paradis ${ }^{b}$
}

Purpose: This study investigated whether past tense use could differentiate children with language impairment (LI) from their typically developing (TD) peers when English is children's second language ( L2) and whether L2 children's past tense profiles followed the predictions of Bybee's (2007) usage-based network model.

Method: A group of L2 children with LI (L2-LI) and a matched group of L2-TD peers were administered the past tense probe from the Test of Early Grammatical Impairment (Rice \& Wexler, 2001) and the Peabody Picture Vocabulary Test (Dunn \& Dunn, 1997). A representative input corpus provided distributional information for each verb used. Background information was obtained via parent questionnaire.

Results: The L2-LI group used fewer tense-marked verbs than did the L2-TD group. In both groups, vocabulary size and word frequency predicted accuracy with regular and irregular verbs. Children omitted regular past tense marking most often after alveolar stops, dropping the allomorph /Id/; L2-TD children omitted / $t /$ more often than /d/. Finally, first language typology predicted past tense accuracy.

Conclusions: Past tense use could potentially differentiate between English L2 children with and without $L$. The impact of vocabulary, frequency, and phonological factors supported the network model and indicated profile differences between L2-LI and L2-TD children.

Key Words: child second language acquisition, language impairment, English past tense, usage-based theory
M uch research has focused on investigating the relationship between the developmental profiles of monolingual children with language impairment (LI) and their typically developing (TD) peers regarding the acquisition of verb inflection in English (Bedore \& Leonard, 1998; Bishop, Adams, \& Norbury, 2006; ContiRamsden, 2003; Redmond \& Rice, 2001; Rice, Wexler, \& Hershberger, 1998; Rice, Wexler, Marquis, \& Hershberger, 2000). This research has shown that English-speaking children with LI have profound difficulties in acquiring tense-marking verbal inflection. Hence, their development

\footnotetext{
${ }^{\mathrm{a}}$ University of Amsterdam, the Netherlands

${ }^{\mathrm{b}}$ University of Alberta, Edmonton, Canada

Correspondence to Elma Blom, who is now at Utrecht University, the Netherlands: w.b.t.blom@uu.nl

Editor: Janna Oetting

Associate Editor: Lisa Bedore
}

Received May 10, 2011

Revision received October 28, 2011

Accepted May 29, 2012

DOI: $10.1044 / 1092-4388(2012 / 11-0112)$ of this particular aspect of the language constitutes a reliable clinical marker, that is, it discriminates well between TD children and children with LI (Rice, 2003; Rice \& Wexler, 2001). Because speech-language pathologists in North America often work with children who are learning English as a second language (L2; Goldstein, 2004; Gutiérrez-Clellen, 1996; Jacobson \& Schwartz, 2005), increasing our understanding of how TD children and children with LI acquire tense inflection when English is their L2 could be relevant to clinical practice. On the one hand, research comparing L2-TD children to their monolingual peers with LI has shown overlap in their difficulties with tense-marking morphology in English, suggesting that use of tense morphology might not differentiate between affected and unaffected children among L2 learners (Paradis, Rice, Crago, \& Marquis, 2008). On the other hand, research comparing the use of tense morphology by English L2 learners with and without LI suggests that accuracy with tense has the potential to be a clinical marker in L2 English (Jacobson \& Schwartz, 2005; Paradis, 2008). The primary goal of this study was to determine the extent to which English L2 children with and without LI differ in their acquisition of the past tense. 


\section{Complimentary Author PDF: Not for Broad Dissemination}

The secondary goal of the study was to investigate what factors predict past tense learning in the context of L2 acquisition according to Bybee's usage-based network model (Bybee, 1995, 2001, 2007) and, in so doing, to examine the broader past tense acquisition profiles of L2 children, with and without LI, beyond simple accuracy. Regarding past tense learning, the network model assumes that regular and irregular past tense are learned in the same way. A first prediction tested in this study is that the same factors that influence children's accuracy with irregular past tense marking should also have an impact on their accuracy with regular past tense. Although some studies on monolingual children with LI have confirmed that vocabulary size and word frequency predict accuracy with both regular and irregular past tense (Marchman, Wulfeck, \& Ellis Weismer, 1999; Oetting \& Horohov, 1997; Van der Lely \& Ullman, 2001), other studies have not (Redmond \& Rice, 2001; Rice et al., 2000), prompting the need for further research on this issue. A second prediction that follows from network model assumptions is that the phonological form of the verb could play a role in acquiring past tense marking. Previous research on monolingual English-speaking children with LI has found evidence for this hypothesis (Eyer \& Leonard, 1994; Johnson \& Morris, 2007; Norbury, Bishop, \& Briscoe, 2001; Oetting \& Horohov, 1997; Rice et al., 2000). What is largely unknown is whether vocabulary size, word frequency, and phonological form also influence L2 past tense acquisition.

Third, we also apply the network model to reveal profile differences between L2-TD children and L2 children with LI. From network model assumptions, it follows that past tense development is a function of building a lexicon, and hence, deficits in building a lexicon, as observed in children with LI, would be expected to affect these children's past tense use (Edwards \& Munson, 2009). By combining lexical deficits in children with LI with the frequently reported observation that these children have limited processing abilities (Leonard et al., 2007; Miller, Kail, Leonard, \& Tomblin, 2001; Windsor \& Huang, 1999), we tentatively propose a usage-based approach that can account for the unique profile of children with LI regarding morphological acquisition.

\section{Past Tense Acquisition: Accuracy and Error Types}

Research has shown that English-speaking children with LI have profound difficulties using tense-marking inflection on verbs when compared with their TD age peers, particularly in the early elementary school years (Bedore \& Leonard, 1998; Bishop et al., 2006; Conti-Ramsden, 2003; Redmond \& Rice, 2001; Rice et al., 1998, 2000). Various studies have found that monolingual children with
LI performed below TD language-matched children with regular past tense and thus that regular verbs differentiate between TD children and children with LI (Leonard, Bortolini, Caselli, McGregor, \& Sabbadini, 1992; Oetting \& Horohov, 1997; Rice, Wexler, \& Cleave, 1995). These studies did not find a between-group difference for irregular past tense. Also, the advantage of regular past tense over irregular past tense, found for TD children, does not generalize to children with LI (Van der Lely \& Ullman, 2001). Other studies have established that children with LI used higher proportions of zero marking than did TD children, for example, "he fall" (Leonard et al., 1992, Marchman et al., 1999; Oetting \& Horohov, 1997; Redmond \& Rice, 2001), whereas TD children overregularized more often, for example, "catched" (Leonard et al., 1992, Oetting \& Horohov, 1997; Redmond \& Rice, 2001; Van der Lely \& Ullman, 2001). Such differences in error types suggest more productive use of inflection by TD children - a possibility we investigate in this study.

Two studies have compared tense marking in English L2 children with and without LI. Jacobson and Schwartz (2005) investigated English past tense use in TD children who spoke Spanish as their first language (L1; $N=15)$ and Spanish L1 children with LI $(N=12)$ with regular verbs, irregular verbs, and novel verbs. Overall accuracy was higher for TD children on all verb types. The TD children were more accurate at existing regular verbs than at existing irregular verbs or novel verbs. Children with LI were more accurate at existing irregular verbs than at existing regular verbs or novel verbs. Overregularizations were only $1 \%$ of the errors in children with LI (versus $26 \%$ for the TD children), suggesting that the L2 children with LI lacked a productive past tense system, similar to the findings for monolingual children. Paradis (2008) compared the longitudinal development of be morphemes, the third person singular, and the past tense in English L2 children with language delay or impairment $(N=2)$ to the development of TD English L2 children $(N=9)$, all with Chinese languages as their L1. The affected children had much lower accuracy with the past tense -ed than the TD children, in particular when compared with the difference between the groups in accuracy with be morphemes. Overregularization was not examined in this study. Both Jacobson and Schwartz's (2005) and Paradis's (2008) studies suggest that similar profiles emerge between affected and unaffected children when English is their L1 or their L2. However, both studies had a small number of children, and neither study examined factors that might predict past tense acquisition in L2 learners. Other research has examined factors influencing morphological learning by L2 children, but they have not included L2 children with LI (Blom, Paradis, \& Sorenson Duncan, 2012; Marinis \& Chondrogianni, 2010). Thus, further research examining predictive factors in the L2 acquisition of the past tense including children with LI is warranted. 


\section{A Usage-Based Approach to Learning Past Tense: The Network Model}

The present study is situated within Bybee's usagebased network model (Bybee, 1995, 2001). In the network model, (English) past tense has been discussed extensively, and even though it has been based on developmental patterns of monolingual children (Bybee, 2007), it should also be applicable to L2 acquisition (Bybee, 2008) and therefore to the population investigated in this study. To our knowledge, no study has applied the network model to past tense acquisition by learners with LI in particular, but it is possible that the model would make some unique predictions for learners affected with LI. Therefore, at the end of this section, we speculate on how the network model could be extended to this population and what unique properties of acquisition with LI could be revealed as a result.

In the network model, both regular and irregular past tense verb forms are stored as whole words, even though they are multimorphemic, with associations between them based on phonological and semantic similarities. Figure 1 illustrates associations between regular past tense forms and shows emergent morphological structure based on the similarity of the final consonant and the similarity of meaning of forms. Emergent morphological structure as in Figure 1 is referred to as schematization. In the network model, each token of experience affects memory storage, so each time a child hears a word, the lexical representation of this word becomes stronger; a high word frequency facilitates access to the word and makes both mono- and multimorphemic words more stable. With respect to past tense development, the implication is that word frequency influences children's accurate use of both (monomorphemic) irregular forms and (multimorphemic) regular forms. Type frequency refers to the number of lexemes with which an affix, or its allomorphs, is used. For instance, Figure 1 contains five

Figure 1. Schema with emergent morphological structure for the regular past tense forms played, spilled, spoiled, banned, and rammed, based on Bybee (2001, p. 23).

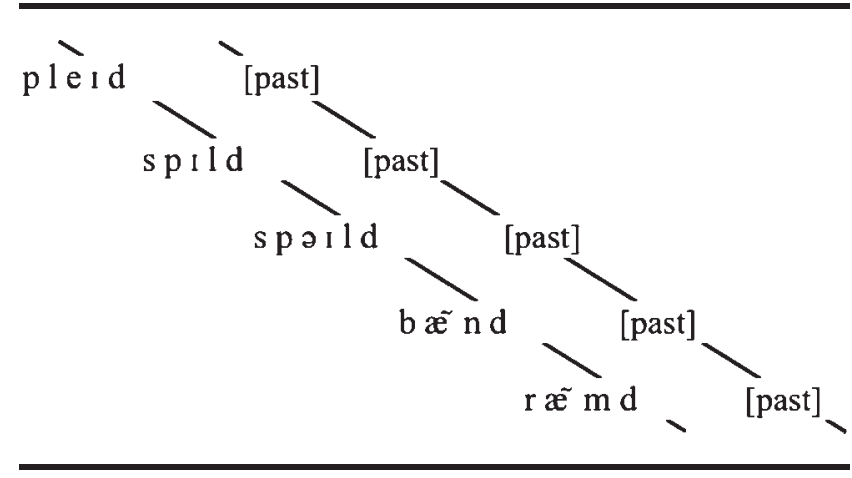

types (played, spilled, spoiled, banned, rammed). A schema with a high type frequency, such as those for the regular past tense allomorphs/t/ and in particular/d/, is productive and is likely to apply to new words. A strong schema for regular past tense marking will lead to temporary overregularizations (e.g., catched) until the correct lexical representation for the irregular verb (e.g., caught) is sufficiently strong. Productivity is moreover a function of the degree of similarity between the words in a schema: The greater the variability of the schema, the more productive the schema will be.

Regular past tense applies to many words that are phonologically very dissimilar, but the allomorphs of -ed do have some phonological restrictions: The allomorph/Id/ is used with verbs that end in an alveolar stop (e.g., wait, decide); / $/$ is used with verbs that end in a voiceless consonant (e.g., stop, dance); and /d/, constituting the largest class, is used with all other regular verbs. Following the logic of the network model, each allomorph will have a separate schema with its own strength based on word frequency, type frequency, and variability, but the allomorphs will be linked together by semantics, that is, the past tense meaning. Many irregular past tense forms in English are isolated, for example, say-said (Bybee, 1995, 2007). Irregular past tense acquisition in English is thus largely dependent on word frequency, in contrast to regular past tense acquisition, which relies on word frequency, type frequency, and variability. The allomorph/Id/, as the least productive of all three regular past tense allomorphs, is, however, expected to rely more on word frequency than the other allomorphs. In particular, the acquisition of / $\mathrm{d} /$, which is the most productive allomorph class, may contrast with the acquisition of $/ \mathrm{Id} /$.

\section{Factors Predicting Past Tense Acquisition in the Network Model}

This study evaluated three predictive factors: vocabulary size, word frequency, and phonological properties of the verb stem. Evaluating the impact of these factors not only allowed testing the specific predictions of the network model for L2 children with and without LI, but it also enabled establishing broader tense-acquisition profiles for these groups.

According to the network model, vocabulary size and word frequency predict accuracy with both regular and irregular past tense forms. The vocabulary size effect is expected because children with large vocabularies can connect more verb types, and so their schemas will be stronger. Correlations between English L1 children's verb vocabulary size and overregularizations of past tense -ed support these predictions (Marchman \& Bates, 1994). However, studies of monolingual English-speaking TD 


\section{Complimentary Author PDF: Not for Broad Dissemination}

children and children with LI (Oetting \& Horohov, 1997; Rice et al., 2000) and African American English-speaking children (Pruitt \& Oetting, 2009) did not find any correlations between vocabulary size and regular past tense use. Also regarding the influence of word frequency, inconsistent findings have been reported. Research on English L1 children revealed that word frequency affects irregular past tense use: English L1-TD children overregularize lowfrequency irregular verbs more often than high-frequency irregulars (Marchman \& Bates, 1994; Maslen, Theakston, Lieven, \& Tomasello, 2004). Word frequency has been found to influence regular past tense use as well, but there are indications that such effects are more pronounced in LI groups than in TD groups (Oetting \& Horohov, 1997) and might only be relevant to TD groups in very early stages (Van der Lely \& Ullman, 2001). Conversely, a study of bilingual French-English TD children showed differential effects in accuracy with the past tense in French and English that were based on differences in the word frequency and type frequency of regular and irregular verbs in each language (Paradis, Nicoladis, Crago, \& Genesee, 2010). These different outcomes regarding effects of vocabulary size and word frequency motivate further research. The present study in particular sought to determine whether findings on the predictive influence for vocabulary size and word frequency for English L1 children would extend to English L2 children, both with and without LI.

The third issue that follows from adopting the network model is whether phonological generalizations affect regular and irregular past tense development. English L1 children use past tense inflection less when verb stems from regular verbs end in an alveolar stop and, conversely, use it more when the stem ends in a vowel or liquid (Berko, 1958; Bybee, 2007; Johnson \& Morris, 2007; Marchman et al., 1999; Norbury et al., 2001; Oetting \& Horohov, 1997). Regular verbs ending in alveolar stops take/Id/, whereas verbs ending in vowels or liquids take $/ \mathrm{d} /$, and this finding may thus reflect that schemas for /Id/ are weaker than schemas for / $d$ / because of differences in distributional properties of these allomorphs (Matthews \& Theakston, 2006). Strength of schemas may predict allomorph variation, but on the basis of the input, a child may also generalize that past tense is expressed by verbs with a word-final /d/ or /t/ (e.g., want, hand), and he or she may also drop/Id/ for this reason. The same schema would also predict few overregularizations with irregular verbs ending in /t/ or /d/ (e.g., hit, stand). Marinis and Chondrogianni (2010) found support for such a phonological pattern in the irregular past tense acquisition of English L1 children, but this observation did not generalize to the English L2 children they studied. Therefore, in the present study, we not only investigated allomorph variation but also reexamined the influence of phonological properties of irregular verbs in English L2 children.
To the best of our knowledge, the network model has not been developed for, or applied to, learners with LI in particular, but here we hypothesize what this model might predict for this group of learners. As mentioned above, all usage-based theories of acquisition, and therefore also the network model, emphasize the prominence of input properties in driving the acquisition process forward. Because these factors are external to the learners, input properties would influence acquisition patterns and rates for children with both TD and LI. The key difference between these groups most likely lies in how effectively they deal with the input. Numerous researchers have argued that limitations in processing capacity are an underlying deficit in LI (Leonard et al., 2007; Miller et al., 2001; Windsor \& Huang, 1999). For example, Leonard et al. (2007) found that limitations in short-term memory and processing speed could be responsible for the language delay exhibited by children with LI. They argued that this is because such limitations would mean it takes longer for children with LI to "intake" the linguistic material from the input, and thus it takes longer for them to establish linguistic representations (Leonard et al., 2007, p. 408). Given network model assumptions, it could be hypothesized that limitations in processing input could impede the development and productivity of schemas, in particular. In the Discussion, we examine our findings, together with those from other studies, with a view to understanding how the unique past tense profiles of children with LI are consistent with the hypothesis that schematization in particular is delayed in these children.

\section{Research Questions for This Study}

The specific research questions guiding this study were as follows:

1. Do L2-TD children more frequently use past tense marking with regular and irregular verbs than L2 children with LI do, and do they also use more overregularization with irregular verbs?

2. Do vocabulary size, word frequency, and stem-final phonemes have an impact on regular and irregular past tense use in L2 children, and is this the same for children with and without LI?

\section{$\overline{\text { Method }}$ Participants}

Forty-eight 5- and 6-year-old children who were learning English as an L2 participated in this study: 24 children with typical language development (L2-TD) and 24 children with language impairment (L2-LI). All children lived in a Canadian English-majority city, either Edmonton or 


\section{Complimentary Author PDF: Not for Broad Dissemination}

Toronto. Children were recruited mainly through schools but also through agencies that offer assistance to newcomer families. For the purposes of the study, the phrase English L2 learners was defined as follows: (a) Both parents were foreign-born and native speakers of a language other than English; (b) children were exposed to no or very limited English until the age of 2 to 3 years or older; and (c) children's onset of consistent and systematic English exposure began in a preschool or school program (mean age of L2 onset $=42.3$ months, range $=7-62, S D=$ 10.5). Children from families where English was used by the parents with the child from birth were excluded, as were children whose exposure to English began in infancy in a day care setting. In this sample, $27 \%$ of the children were foreign born.

The L2-LI group consisted of children who were recruited through two methods: (a) caseloads of school-based speech-language pathologists and (b) special kindergarten programs for children with language or cognitive delays. Canadian-certified speech-language pathologists were part of the educational team in these programs, and the children with LI were referred to us by them. Regardless of how they were recruited, all L2 children with LI had undergone speech-language assessments. We did not have access to test scores; however, as part of the recruitment process, we requested referrals to English L2 children who exhibited language delay or impairment but who did not have hearing impairment, autism spectrum disorder, acquired neurological damage, or clinically significant cognitive limitations, for example, Down syndrome. We also requested that children who presented primarily with speech-sound disorders not be referred.

The children in this study were selected from a larger sample of L2 children who were TD or had LI (Paradis, Emmerzael, \& Sorenson Duncan, 2010). This subsample was selected to form two matched groups. Each child in the L2-LI group was matched to a TD child on age at testing; length of L2 exposure; L1 typology; and, to the extent that this was possible, mother's education. Information for these matching criteria was gathered using a parental questionnaire, the Alberta Language Environment Questionnaire (Paradis, 2011; www.chesl.ualberta.ca). For matching on age and exposure, a 4-month range was used. If no exact L1 match was available within the sample of children with the matching age and exposure, the L1 match was based on whether the L1 expressed tense through inflection on the verb (L1 typology). Eleven pairs were matched exactly in their L1, and 13 pairs were matched on L1 typology. There were nine pairs of children with typologically isolating L1s where tense is not expressed through inflection on the verb $(n=18)$ : Cantonese $(n=10)$, Mandarin $(n=1)$, Cantonese/Mandarin $(n=2)$, and Vietnamese $(n=5)$ (Lin, 2001; Matthews \& Yip, 1991; Thompson, 1987). Fifteen pairs of children had a typologically inflecting L1 that expresses tense on the verb $(n=30)$ : Arabic $(n=4)$, Assyrian $(n=1)$, Gujarati $(n=3)$, Portuguese $(n=1)$, Punjabi $(n=4)$, Somali $(n=1)$, Spanish $(n=13)$, and Urdu $(n=3)$ (Bateson, 1967; Bhatia, 1993; Butt \& Benjamin, 2004; Kachru, 2006; Mercer, 1961; Saeed, 1993; Schmidt, 1999).

Because bilingual children with LI display deficits in both their languages (Paradis, Genesee, \& Crago, 2011), it is important to consider L1 development in this group. For the majority of the children in the L2-LI group, the speech-language pathologists indicated to us that there was some parent concern about their child's L1 development; however, this information was not gathered in a systematic way. As a part of the testing procedures for the present study, the parents were given a questionnaire about their child's L1 development, the Alberta Language Development Questionnaire (ALDeQ; Paradis, Emmerzael, \& Sorenson Duncan, 2010; www.chesl.ualberta.ca). The ALDeQ is focused on children's L1 development and consists of four sections: early milestones, current L1 abilities, behavior patterns and activity preferences, and family history. The ALDeQ yields proportion scores between 0 and 1.0, where higher scores signify responses more characteristic of typical development.

The ALDeQ scores in Table 1 show significantly lower scores for the LI group compared with the TD group. All children in the TD group scored within the one standard deviation range reported for TD children by Paradis, Emmerzael, \& Sorenson Duncan (2010) (range = .69-.93). In the LI group, 19 children scored within the one standard deviation range reported for this group by Paradis, Emmerzael, \& Sorenson Duncan (2010) (range = .33-.67). Three children with LI scored below this range, whereas two other children scored just above this range (.70 and .73). Hence, the overlap between the ALDeQ scores for the two groups was minimal. The children with LI had lower nonverbal IQ scores than the L2-TD group, as measured with the Columbia Mental Maturity Scale (Burgemeister, Hollander Blum, \& Lorge, 1972). In the LI group, two children scored below the normal range $(<85)$ with standard scores of 79 and 83; for this reason, we refer to the group with lower language abilities as having LI instead of "specific" LI. In the TD group, two children also scored below the normal range (scores: 83, 84). There was no difference between the two groups in their receptive vocabulary scores measured with the Peabody Picture Vocabulary Test (Dunn \& Dunn, 1997). Finally, all except two children in the LI group passed the phonological probe of the Test of Early Grammatical Impairment (TEGI screener; Rice \& Wexler, 2001), which indicated children's ability to produce the word-final consonants needed for past tense use. The children who failed were still included in the study because they could produce some of the wordfinal /t/ and /d/ sounds on the phonological probe, and furthermore, they produced some responses with word-final consonants on the past tense probe, either as verb stems 
Table 1. Characteristics of the English L2 children.

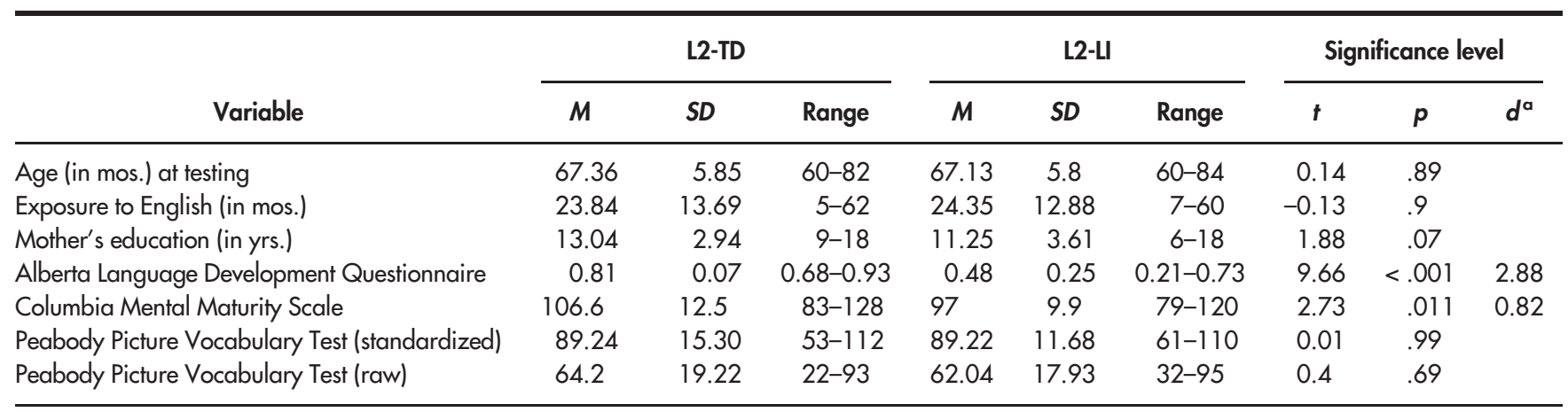

Note. $\mathrm{L} 2$ = second language; $T D=$ typically developing; $L I=$ language impairment.

aEffect size measure Cohen's $d$ to indicate the magnitude of a difference.

or overregularizations. So it did not seem that their low performance on the past tense probe could reasonably be attributed to phonological constraints. Also, some other children who passed the phonological probe had the same scores on the past tense probes as these two children, so their scores on the past tense probe were not outliers.

\section{Measures}

The dependent variables of the study are based on children's responses on the past tense probe of the TEGI screener (Rice \& Wexler, 2001). The TEGI past tense probe consists of pairs of pictures, showing a child engaged in an activity on one picture and the child having completed the activity in the second picture. The research assistant showed a practice set of pictures and said, "Here the boy is raking" (showing the first picture), "Now he's done" (referring to the second picture), and "Tell me what he did to the leaves?" There are 10 regular verbs and eight irregular verbs on the probe; one verb (rake) was used for practicing. Sometimes children produced other verbs than the verbs targeted by the TEGI; those verbs were included. In total, the children used 28 different regular and 24 different irregular verbs (see Appendix for TEGI verbs and verbs used by the children).

Following TEGI guidelines, scorable responses were target like (e.g., ate, kicked), zero marking (e.g., eat, kick), overregularization (e.g., eated), or double-marked forms (e.g., ated, kickeded). Other responses were classified as unscorable. The children produced 586 scorable responses on the past tense probes; 278 responses were unscorable. Unscorable responses were equally distributed across groups $(\mathrm{LI}=39 \%$, $\mathrm{TD}=26 \%$; L1 with tense-marking inflection $=31 \%$, isolating $\mathrm{L} 1$ without tense-marking inflection $=35 \%$ ).

Word frequencies were measured using the Edmonton English Language Learners (ELL) corpus. This corpus contains language samples from English L2 children and adult native speakers of English, all living in the Edmonton area. These language samples have been collected as part of several studies over 8 years conducted by the second author (e.g., Golberg, Paradis, \& Crago, 2008; Paradis, 2008; Paradis et al., 2008; Zdorenko \& Paradis, 2008, 2012). The samples were collected in a naturalistic setting and can be considered representative of the input of English L2 children in Edmonton. Previous research indicated that the Edmonton ELL corpus, although relatively small, yielded word and lemma frequency effects for English L2 children's use of third person singular $-s$, whereas no relations emerged using the much larger Corpus of Contemporary American English (Blom et al., 2012). The children in the present study are part of the Edmonton ELL corpus, but their transcripts were left out of the frequency calculations for this study. At time of compilation, the corpus for this study consisted of 223,530 words, coming from 122 children and seven adults; $56 \%$ of utterances in the corpus were produced by adults, and $44 \%$ were produced by the children. All utterances in the Edmonton ELL corpus were transcribed and morphologically tagged (MacWhinney, 2008, 2010). Frequency lists were created for counting word frequency for each verb produced. Word frequency was the number of past tense forms of a given $\operatorname{verb}$ (range $=0-395)$. Lemma frequency $($ range $=0-2164)$ was counted to control for confounding effects of word and lemma frequency (Pinker \& Ullman, 2002). Lemma frequency is the sum of all the different inflected forms of a given verb (bare stem, third person singular, past tense, progressive, and past participle). The tagging procedure did not provide tags for erroneous forms, which were sometimes used by the L2 children in the corpus; as a result, overregularized and double-marked past tense forms were not included in the frequency counts.

\section{Procedure}

The study was reviewed and approved by the Health Research Ethics Board at the University of Alberta. 
Children were tested in English either in their homes or at school, and parents were visited at home for the questionnaires. Research assistants were all native speakers of Western Canadian English. For home visits, the research assistant was accompanied by a cultural broker or interpreter if the parents' English was not fluent; this occurred in the majority of cases. Children's responses on the past tense probes were written out on the TEGI response forms during the test and scored afterward, following TEGI guidelines as outlined above. All scoring was done by native speakers of English, and any discrepancies were solved by consensus.

\section{$\overline{\text { Results }}$ \\ Between-Group Comparisons}

The first research question addressed differences between the L2-TD and L2-LI groups first by comparing their use of past tense marking collapsing regular and irregular verbs and second by comparing types of errors with irregular verbs across the two groups. The raw data pertaining to tense marking and error types across the two groups are summarized in Table 2.

In the L2-TD group, 50\% (160 of 321) of all responses contained a verb marked for past tense. For regular verbs, $50 \%$ of the responses contained an inflected verb, and for irregular verbs, $49 \%$ were marked for tense. For the L2-LI group, 28\% (74 of 265) of all responses had a verb marked for past tense: $26 \%$ of the regular verbs and $30 \%$ of the irregular verbs were tense-marked. To compare past tense marking across the two groups, we calculated proportions of tense-marked verbs for each child, collapsing regular and irregular verbs (past tense overall), and based on these individual proportions, a mean proportion of tensemarked verbs for each group was calculated. Target-like responses, overregularizations, and double past tense markings ("productive errors") were counted as correct responses: These responses indicate the ability to use past tense inflection. Zero markings were scored as incorrect responses. Individual proportions based on a denominator smaller than three were excluded, because such proportions may not be representative. Data from

Table 2. Raw data for groups, verb type, and error type

\begin{tabular}{|c|c|c|c|c|c|c|c|}
\hline \multirow[b]{2}{*}{ Group } & \multicolumn{2}{|c|}{ Regular } & \multicolumn{3}{|c|}{ Irregular } & \multirow{2}{*}{$\begin{array}{c}\text { Total: } \\
\text { RC + ROM + } \\
\text { IC + IOR + IOM }\end{array}$} & \multirow{2}{*}{$\begin{array}{l}\text { Tense marked } \\
R C+I C+I O R\end{array}$} \\
\hline & RC & ROM & IC & IOR & IOM & & \\
\hline L2-TD & 87 & 86 & 35 & 38 & 75 & 321 & 160 \\
\hline L2-LI & 35 & 99 & 19 & 20 & 92 & 265 & 74 \\
\hline
\end{tabular}

Note. $\mathrm{RC}=$ regular correct; $\mathrm{ROM}=$ regular omission; $\mathrm{IC}=$ irregular correct; $I O R$ = irregular overregularization; $I O M=$ irregular omission. two children with LI were left out for this reason; the mean number of responses per included child was 13 (range $=3-18, S D=4.90$ ). Comparisons of the resulting group means confirmed that TD children $(M=45 \%, S D=$ 36) tended to mark tense more often than did children with LI $(M=26 \%, S D=31), t(43)=1.96, p=.057$. This marginally significant difference was due to one outlier, that is, the dot in Figure 2. Exclusion of this child led to a lower mean percentage of tense-marked verbs in the LI group $(M=21 \%, S D=27)$ and a significant difference between TD and LI, $t(42)=2.47, p=.018 ; d=0.76$.

Regarding error types, $36 \%$ of the errors with irregular verbs in the L2-TD group were overregularizations; in the L2-LI group, this was $18.5 \%$. Mean proportions of overregularizations were calculated per group on the basis of individual proportions of overregularizations (i.e., for each child, the number of overregularization errors divided by the sum of overregularizations and omissions). Five children for whom the denominator was smaller than three were thus excluded. Children in the L2-TD group $(M=31 \%, S D=33)$ used more overregularization than did children in the L2-LI group $(M=15 \%, S D=22)$ even when two outliers in the L2-LI group (see Figure 3) were included, $t(32)=2.08, p=.046 ; d=0.73$.

\section{Mixed Logistic Regression: Past Tense Overall}

We used logistic mixed-effects modeling to assess the effect of multiple variables on L2 children's past tense marking. The first regression analysis was run on past tense overall and looked at the impact of LI on children's ability to mark tense when the influence of other factors, such as L1 typology, nonverbal IQ, vocabulary size, and word frequency, is also taken into account. Randomeffect factors were Child and Verb. Fixed-effect factors were

Figure 2. Proportion of tense-marked verbs in the L2-TD and L2-LI group (past tense overall).

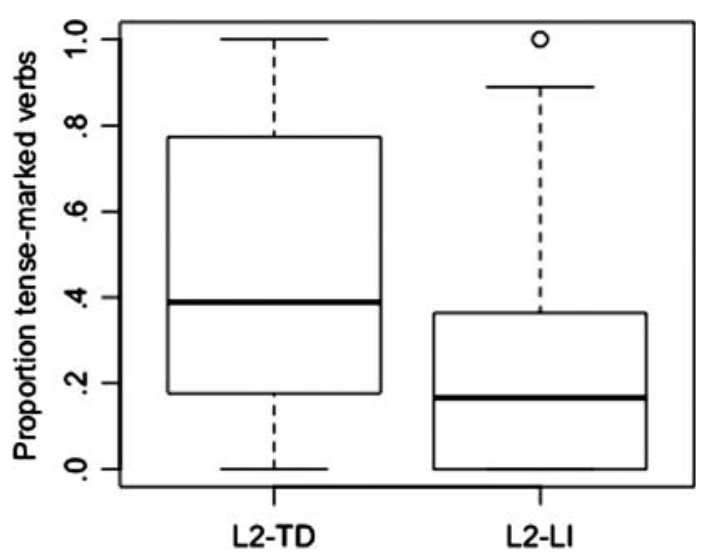


Figure 3. Proportion of overregularizations in the L2-TD and L2-LI group (irregular past tense).

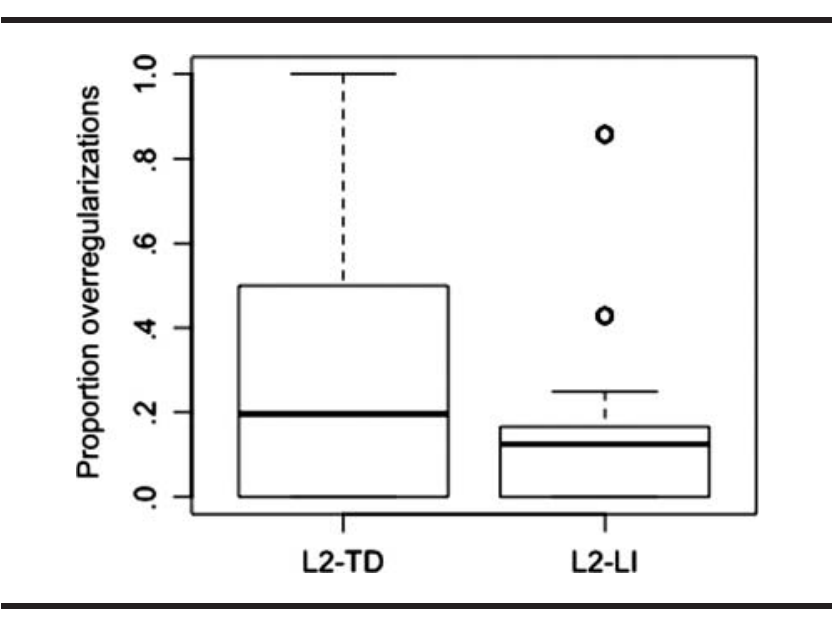

modeled by means of contrast between levels, where each level of a factor is contrasted to a specified reference level (treatment-coding). TDORLI (TD, LI) indicated whether a child belonged in the TD or in the LI group - the reference level is in bold. L1TYP (noTNS, TNS) contained information about a child's L1: Cantonese, Mandarin, or Vietnamese were coded as "noTNS," whereas Arabic, Assyrian, Gujarati, Portuguese, Punjabi, Somali, Spanish, or Urdu were coded as "TNS" (for L1s with tense marking). CMMS was the raw score on the Columbia Mental Maturity Scale and was included to control for between-group differences in nonverbal IQ. Vocabulary was children's receptive vocabulary size based on their raw Peabody Picture Vocabulary Test score. WORDFREQ was the log-transformed word frequency in the Edmonton ELL corpus. Because word frequency and lemma frequency (LEMFREQ) were highly correlated, $r(50)=0.85, p<.001$, a decorrelated word frequency predictor (WORDFREQ-RESID) was created by predicting the variation in WORDFREQ by LEMFREQ; WORDFREQ-RESID are the residuals of this model. The correlation between WORDFREQ and WORDFREQRESID was significant, $r(50)=0.63, p<.001$.

Predictor variables in the full model for past tense overall were TDORLI, CMMS, L1TYP, Vocabulary, WORDFREQ-RESID, and LEMFREQ. Starting with the full model with all predictor variables, we applied backward elimination to obtain a simple model with only predictors for significant main effects. After that, model complexity was increased by adding interactions. To decide whether variables should be retained in the model, likelihood ratio tests were applied to compare nested models. The model estimates for the resulting optimal model are shown in Table 3. Children in the LI group used fewer tense-marked verbs and had more zero-marking errors than did children in the TD group $(p=.049)$. The effect of L1TYP indicated that tense marking was more frequent in children with a tense-marking L1 than in children
Table 3. Optimal logistic regression model for past tense overall.

\begin{tabular}{lrrrr}
\hline Predictor variable & Estimate & SE & $\boldsymbol{Z}$ & $\boldsymbol{p}$ \\
\hline Intercept & -5.68 & 1.97 & -2.88 & .004 \\
TDORLI (LI) & -1.34 & 0.68 & -1.97 & .049 \\
LITYP (TNS) & 1.46 & 0.67 & 2.19 & .028 \\
CMMS & -0.05 & 0.04 & -1.11 & .267 \\
Vocabulary & 0.09 & 0.02 & 4.74 & $<.001$ \\
WORDFREQ-RESID & 0.65 & 0.23 & 2.79 & .005
\end{tabular}

Note. TDORLI = group, either typically developing or language impairment; LITYP = first language typology; TNS = first language with tense marking; $C M M S$ = raw score on Columbia Mental Maturity Scale (nonverbal IQ); Vocabulary = raw score on Peabody Picture Vocabulary Task (receptive vocabulary); WORDFREQ-RESID = word frequency (residuals).

whose L1 did not express tense on the verb ( $p=.028)$. Children with larger receptive vocabularies used more tense-marked verbs than did children with smaller receptive vocabularies $(p<.001)$. Finally, past tense forms with a higher word frequency were also used more often with past tense marking ( $p=.005)$. TDORLI emerged as a significant predictor only if CMMS was also included in the model. The model with TDORLI and CMMS was preferred over the model without these predictors, $\chi^{2}(2)=$ $27.54, p<.001$.

To produce a statistic to judge the fit of the logistic model, we calculated the Concordance Index (C; Chatterjee $\&$ Hadi, 2006); as a rule of thumb, a $\mathrm{C}$ value above 0.8 indicates that the model has good performance. The optimal model for past tense overall was accurate $(C=0.93)$.

\section{Mixed Logistic Regression: Regular and Irregular Past Tense}

Two further regression analyses looked at regular and irregular past tense separately, with the goal of answering the second research question and testing the predictions of the network model. In these analyses, only target-like responses were treated as correct responses to ensure a direct relationship between input frequencies and the outcome variable. Note that investigating targetlike performance for irregulars is not only relevant for testing the network model predictions, but it could also contribute to establishing a unique acquisition profile for LI: If affixal marking in particular, that is, schematization, is compromised in children with LI, it is expected that the groups will differ in accuracy with regular marking, whereas accuracy with irregular markings will not differ.

Predictor variables in the full models were TDORLI, L1TYP, CMMS, Vocabulary, WORDFREQ-RESID, LEMFREQ, and, for regular past tense, Allomorph. "Allomorph" (/Id/,/d/,/t/) described phonological properties of the verb stem: Regular verbs that ended with an 


\section{Complimentary Author PDF: Not for Broad Dissemination}

alveolar stop were coded for /Id/ $(n=5)$, verbs with a stem-final voiceless phoneme for $/ \mathrm{t} /(n=11)$, and the rest for $/ \mathrm{d} /(n=12)$.

Table 4 lists the model estimates for the optimal model for regular past tense. Starting with those effects that appeared only as main effects, we observe that children with larger receptive vocabularies were more accurate than children with smaller receptive vocabularies $(p<.001)$, and higher accuracies were found as an effect of word frequency ( $p=.046$ ). The children were less accurate with using the allomorph /Id/ than with $/ \mathrm{t} /(p=.005)$ or $/ \mathrm{d} /(p<.001)$; these differences remain significant after Bonferroni adjustment $(p<.025)$. TD children made fewer errors with supplying the allomorph $/ \mathrm{d} /$ than $/ \mathrm{t} /$, whereas the reverse pattern can be observed for the LI group $(p=.051)$. The model with CMMS was preferred over the model without CMMS, $\chi^{2}(1)=19.05, p<.001$. The optimal model provided a good fit $(\mathrm{C}=0.94)$.

Table 5 summarizes the optimal model for irregular past tense. Children with a tense-marking $\mathrm{L} 1$ were more accurate than children whose L1 did not express tense on verbs ( $p=.034$ ), children with larger receptive vocabularies were more accurate than children with smaller vocabularies $(p=.003)$, and both word frequency ( $p=.016)$ and lemma frequency ( $p=.015$ ) determined children's accuracy with irregular past tense. TDORLI did not emerge as a significant predictor in the best-fitting model. The model made accurate predictions $(\mathrm{C}=0.96)$.

\section{Follow-Up Analyses: Effects of Phonological Properties}

We performed two follow-up analyses to investigate the role of phonological properties of the verb more in depth. First, overregularizations were compared across two phonological categories within the sample of irregular verbs: verbs with a stem-final/d/or/t/ and verbs with a stem that ended in other sounds. If children assume

Table 4. Optimal logistic regression model for regular past tense.

\begin{tabular}{lrrrc}
\hline \multicolumn{1}{c}{ Predictor variable } & Estimate & SE & $\boldsymbol{Z}$ & $\boldsymbol{p}$ \\
\hline Intercept & -2.47 & 2.51 & -0.98 & .325 \\
TDORLI (LI) & -3.50 & 1.21 & -2.90 & .000 \\
CMMS & -0.09 & 0.07 & -1.36 & .174 \\
Vocabulary & 0.09 & 0.03 & 3.33 & .001 \\
WORDFREQ-RESID & 0.51 & 0.26 & 2.00 & .046 \\
Allomorph (/Id/) & -2.30 & 0.63 & -3.62 & .000 \\
Allomorph (/t/) & -0.69 & 0.58 & -1.33 & .184 \\
TDORLI (LI) $\times$ Allomorph (/Id/) & 1.48 & 1.18 & 1.25 & .211 \\
TDORLI (LI) $\times$ Allomorph (/t/) & 1.86 & 0.95 & 1.95 & .051 \\
\hline
\end{tabular}

Note. Allomorph $=$ allomorphs of regular past tense; $/ \mathrm{Id} / \mathrm{l}=$ regular past tense allomorph /Id/; / $/$ / = regular past tense allomorph $/ \mathrm{t} /$.
Table 5. Optimal logistic regression model for irregular past tense.

\begin{tabular}{lrrrr}
\hline Predictor variable & Estimate & SE & $\boldsymbol{Z}$ & $\boldsymbol{p}$ \\
\hline Intercept & -15.46 & 3.38 & -4.57 & $<.001$ \\
LITYP (TNS) & 2.31 & 1.09 & 2.12 & .034 \\
Vocabulary & 0.11 & 0.04 & 2.93 & .003 \\
WORDFREQ-RESID & 1.06 & 0.44 & 2.42 & .016 \\
LEMFREQ & 0.64 & 0.26 & 2.44 & .015 \\
\hline
\end{tabular}

Note. $L E M F R E Q=$ lemma frequency.

that a verb-final /d/ or /t/ sound expresses a past tense meaning (Bybee, 2001, 2007), fewer overregularizations are expected with irregular verbs with a stem-final /d/ or / $/$ / than with other irregular verbs. The outcome of a one-tailed chi-square test confirmed this prediction and indicated that irregular verbs with a stem-final /t/ or $/ \mathrm{d} /$ $\left(N_{\text {overregularization }}=16, N_{\text {zero marking }}=69\right)$ were overregularized less often than other irregular verbs $\left(N_{\text {overregularization }}=\right.$ $\left.42, N_{\text {zero marking }}=98\right), \chi^{2}(1)=3.45, p=.032$.

Previous research has indicated that children inflect verbs more often with past tense - ed if these verbs end in a vowel or liquid (Marchman et al., 1999; Norbury et al., 2001; Oetting \& Horohov, 1997). Because verbs ending in a vowel or liquid fall in the /d/ allomorph class, it is difficult to assess whether the effect of vowel or liquids exists independent of the effect of allomorph class. Therefore, a second follow-up analysis tested within the allomorph class / $d$ / whether children inflected verbs ending in a vowel or liquid more often than other verbs. It turned out that the children tended to use /d/ more often if the verb ended in a vowel or liquid $\left(N_{\text {correct }}=17, N_{\text {zero marking }}=\right.$ $15)$ than if the verb ended in another phoneme $\left(N_{\text {correct }}=\right.$ $24, N_{\text {zero marking }}=43$ ): The difference between the two types of $/ \mathrm{d} /$ verbs was marginally significant, $\chi^{2}(1)=2.67$, $p=.051$, one-tailed.

\section{$\overline{\text { Discussion }}$}

The primary goal of this study was to investigate whether past tense acquisition profiles are different between L2-TD children and L2 children with LI. We formulated the following research question: Do L2-TD children use past tense marking more frequently with regular and irregular verbs than L2 children with LI do, and do L2-TD also use more overregularization with irregular verbs? Combining regular and irregular verbs, we found that children in the L2-TD group used more past tense marking than did children in the L2-LI group. Error analyses revealed that L2-TD children used more overregularization, and hence made more productive errors, than did L2 children with LI. Regression analyses indicated that L2-TD children were better than L2 children with LI at 
using regular past tense inflection, while the two groups were equally accurate at using irregular past tense forms.

The secondary goal of this study was to test predictions of the network model (Bybee, 1995, 2001, 2007). The guiding research question was, Do vocabulary size, word frequency, and stem-final phonemes have an impact on regular and irregular past tense use in L2 children, and is this the same for children with and without LI? Children's accuracy with both regular and irregular verbs was predicted by vocabulary size and word frequency. For both regular and irregular verbs, phonological effects emerged: Regular past tense marking was more often omitted after alveolar stops, leading to more frequent omission of the allomorph /Id/ than of /t/ or /d/, and irregular verbs ending in an alveolar stop were overregularized less often. The difference between the L2-TD and L2-LI group in using regular past tense marking was most pronounced for regular verbs taking the allomorph /d/. Whereas L2-TD children were quite accurate with this highly frequent regular verb class, L2 children with LI performed rather poorly with this class. Finally, children with a tense-marking L1 were found to be more accurate with tense marking in English than children whose L1 did not mark tense on the verb.

\section{Past Tense Marking in English L2 Children}

The overall difference in accuracy with past tense marking in this study suggests that tense marking abilities are different between English L2 children with and without LI and that, in this respect, L2 profiles resemble L1 profiles, in line with findings of Jacobson and Schwartz (2005) and Paradis (2008). Also in line with previous studies, both on L1 and L2, were the findings that children with LI made fewer overregularization errors than did TD children and the absence of a between-group difference for the accurate use of irregular past tense marking (L2 children: Jacobson \& Schwartz, 2005; L1 children: Leonard et al., 1992; Oetting \& Horohov, 1997; Redmond \& Rice, 2001; Rice et al., 1995). Both observations support the conclusion that the productive use of past tense inflection, that is, schematization of past tense, is compromised in children with LI, and that this is the same for children regardless of whether English is their L1 or L2.

Jacobson and Schwartz (2005) found that L2-TD children were more accurate with regular verbs than with irregular verbs, whereas L2 children with LI showed the reverse pattern. In our study, both groups marked past tense about equally frequently on regular and irregular verbs. Two differences between the studies could be relevant. First, in Jacobson and Schwartz's study, overregularizations were counted as incorrect, whereas we treated them as correct. This last classification may obscure difficulties with using target-like irregular past tense forms in the L2-TD group, because children in this group overregularized relatively frequently. Second, the children in Jacobson and Schwartz's study were on average 96 months old, with a mean length of U.S. residence of 74 (L2-TD) and 81 months (L2-LI), respectively, and thus, they were older than the children in our study and had longer exposure times. After longer exposure, schematization may cause a developmental "jump" for regular past tense (Marchman \& Bates, 1994). Irregular past tense will develop more gradually because of the limited possibilities for schemas-hence the importance of individual word, or token, frequency. Therefore, developmental differences between the two past tense forms may surface after longer exposure, and this could explain why these results emerged in Jacobson and Schwartz's study and were absent in our study.

If L2 children with TD have greater accuracy with past tense marking than L2 children with LI do, does this mean that past tense is a good clinical marker of LI among L2 learners? The results of this study cannot answer this question fully. First, according to prior research on monolingual acquisition with LI, a reliable clinical marker discriminates well between the affected and unaffected group, meaning there is limited overlap between the distributions (see especially Rice, 2003). Our data indicate that even though between-group differences in the means were found, there is substantial overlap between them (cf. Figures 2 and 3). Second, additional analyses using techniques better suited to determining the discriminatory properties of past tense use would be necessary to know the extent to which past tense use could function to identify children with LI among L2 learners. Nevertheless, the results of this study, together with those of Jacobson and Schwartz (2005) and Paradis (2008), indicate that further investigation into past tense as a clinical marker in L2 English would be worthwhile. We recommend that past tense use in particular be investigated in combination with other measures as, ultimately, combinations of measures may be needed to identify children with LI (Oetting, Cleveland, \& Cope, 2008).

\section{Influence of Vocabulary, Frequency, and Phonology on Past Tense Marking}

The impact of vocabulary size and word frequency on accuracy with regular and irregular past tense confirmed predictions of the network model for past tense acquisition. Effects of vocabulary size were also reported in previous research on English L1 children (Marchman \& Bates, 1994). Effects of word frequency are consistent with previous findings on English L1 children (Marchman et al., 1999; Maslen et al., 2004; Oetting \& Horohov, 1997; Van der Lely \& Ullman, 2001), French-English bilingual children (Paradis, Nicoladis, et al., 2010), and English L2 children (Marinis \& Chondrogianni, 2010). 


\section{Complimentary Author PDF: Not for Broad Dissemination}

Van der Lely and Ullman (2001) concluded that word frequency effects on regular past tense development were less relevant for TD controls than for children with LI. In the regression analyses, we did not find any interaction effects that could point to such a difference. Again, developmental stage may be a key to understanding this inconsistency across studies. Given a mean exposure to English of 2 years (range $=5-60$ months) and a relatively low proportion of tense-marked verbs - even in the TD group, this was only 50\% - it can be concluded that many children in our sample must have been in a relatively early stage in which the effects of vocabulary size and word frequency - or, more in general, word learningwill be stronger than in later stages when schemas for regular past tense have emerged. This is consistent with Van der Lely and Ullman's (2001) observation that only the youngest TD group showed a frequency effect for regular past tense marking. The monolingual children in the other studies have had more years of exposure to English and used more tensed-marked verbs than the children in our study, and hence, effects of vocabulary size and word frequency may have been absent as a result of their being in a later developmental stage.

The allomorph variation, indicating effects of phonological properties of the stem, in the present study confirms that the children are still developing schemas for regular past tense. The low accuracy for /Id/ replicates previous findings (Berko, 1958; Bybee, 2007; Johnson \& Morris, 2007; Marchman et al., 1999; Norbury et al., 2001; Oetting \& Horohov, 1997). Dropping the /Id/ suggests that children are using a schema that states that verbs that end in / $/$ / or /d/ are acceptable past tense forms (Bybee, 2007). The use of such a schema is further supported by the observation that the children overregularized less often with irregular verbs that had a stem-final /d/ or /t/. In addition, the low type frequency of /Id/ may contribute to its late acquisition (Berko, 1958; Matthews \& Theakston, 2006). The allomorph $/ d /$ has the highest type frequency in English, which would explain why L2-TD children show their highest accuracies with this allomorph. Marinis and Chondrogianni (2010) did not find sensitivity to phonological patterns in English L2 children's use of irregular past tense: In their study, the L2 children overregularized irregular forms regardless of their phonological properties. These children had, on average, 4 years of exposure to English, and it would be plausible that as a result of increasingly stronger schemas for regular past tense, weaker irregular verb schemas were overridden.

\section{Extending the Network Model to Language Impairment in an L2 Context}

Many studies have indicated that children with LI have slower processing speed or reaction times and less efficient verbal short-term memory (Leonard et al., 2007;
Miller et al., 2001; Windsor \& Huang, 1999). Such processing limitations might affect the amount and quality of linguistic information that children store in long-term memory (see especially Leonard, 1998; and Leonard et al., 2007) and could impact the number of items in the linguistic representation as well as the phonological and semantic details associated with these items. It is worth considering in more detail how the processing limitations that accompany language impairment could lead to atypical development of affixal or regular past tense in English, following the network model approach. Under the circumstances of typical development, high type frequency and low phonological restrictions permit productive schematization of regular past tense forms. But if storing enough regular past tense verb types with sufficient phonological and semantic detail takes more time, as may be the case for children with LI, productive schematization will be delayed, and consequently, use of correct regular past tense forms might be more dependent on token-based or word-byword learning. The end result would be reduced use of correct past tense forms in the speech production of children with LI, because it is the combination of both token- and type-based learning that promotes productive and accurate use of morphology in the network model.

The hypothesis that children with LI have weak, or perhaps even nonexistent, regular past tense schemas as a result of processing limitations can provide a unified account for different aspects of the linguistic profile of children with LI, as found in this and other studies, beyond accuracy. First, if children with LI have reduced abilities to use type frequency information, leading to longer reliance on word frequency information for regular past tense, this could explain the more pronounced effects of word frequency on regular past tense acquisition in children with LI (Oetting \& Horohov, 1997; Van der Lely \& Ullman, 2001). Second, irregular past tense acquisition relies heavily on word frequency because inherent properties of irregular verbs permit little schematization. Therefore, the inherent properties of these verbs put children with LI somewhat on equal footing with TD children with respect to acquiring the correct forms of irregular verbs. This could explain why researchers often find fewer differences between TD children and children with LI in their accuracy with irregular verbs, in contrast to regular verbs (Jacobson \& Schwartz, 2005; Leonard et al., 1992; Oetting \& Horohov, 1997; Rice et al., 1995). Furthermore, the limited productivity of the regular past tense schema would result in fewer overregularizations with irregular verbs because a schema needs to be productive in order to be overgeneralized, and both this study and others have found lower levels of overregularization in children with LI (Jacobson \& Schwartz, 2005; Leonard et al. 1992; Oetting \& Horohov, 1997; Redmond \& Rice, 2001). Finally, in the present study, it was found that only L2-TD children were most accurate at using the 


\section{Complimentary Author PDF: Not for Broad Dissemination}

allomorph /d/, suggesting that these children seemed to be able to make use of the high type frequency of $/ \mathrm{d} / \mathrm{in}$ the input by associating /d/-verb types and forming a schema. In a nutshell, the argument we are putting forward is as follows: A deficit that comes along with language impairment lies in the ability to efficiently process linguistic input. One result of this deficit could be fewer and less detailed lexical representations for verbal paradigms, which, in turn, leads to less productive schematization in the lexicon and a greater reliance on token-based learning of verb forms. Thus, children with LI would show less productivity in the use of regular past tense verb forms in speech as well as the other learning profile characteristics we have just discussed above.

On balance, the results of this study indicate that there are strong parallels between the past tense profiles of typical and atypical learners, whether they are monolingual or bilingual. However, the presence of an L1 does make L2 learners distinct from monolinguals, and L1 background was found to influence children's outcomes. The L1 transfer effects in this study were consistent with findings reported in other child L2 studies (Blom et al., 2012; Paradis, 2011; Zdorenko \& Paradis, 2008, 2012). According to Bybee (2008), L2 learners transfer L1 knowledge on the basis of similarity. Transfer based on exact phonological similarity would be minimal, but prior learning of semantic associations between verbs expressing past time reference, as well as the presence of networks of verb schemas in the L1 lexicon, could support learning these semantic associations and building these networks in the L2. The presence of LI and L1 typology did not interact in our analyses. Therefore, our results indicate that children both with and without LI can benefit from L1 transfer in L2 acquisition.

\section{Acknowledgments}

This research was supported by a Marie Curie International Fellowship within the Seventh European Community Framework Programme (Grant IOF-219276), awarded to Elma Blom, and by grants from Alberta Innovates-Health Solutions (Grant 200800618-2); the Alberta Centre for Child, Family, and Community Research (Grant 090415INV); and the Canadian Language and Literacy Research Network (Grant 27061500), awarded to Johanne Paradis.

\section{References}

Bateson, M. C. (1967). Arabic language handbook. Washington, DC: Center for Applied Linguistics.

Bedore, L., \& Leonard, L. (1998). Specific language impairment and grammatical morphology: A discriminant function analysis. Journal of Speech, Language, and Hearing Research, 41, 1185-1192.
Berko, J. (1958). The child's learning of English morphology. Word, 14, 150-177.

Bhatia, T. K. (1993). Punjabi: A cognitive-descriptive grammar. New York, NY: Routledge.

Bishop, D. V. M., Adams, C. V., \& Norbury, C. F. (2006). Distinct genetic influences on grammar and phonological short-term memory deficits: Evidence from 6-year-old twins. Genes, Brain and Behavior, 5, 158-169.

Blom, E., Paradis, J., \& Sorenson Duncan, T. (2012). Effects of input properties, vocabulary size, and L1 on the development of third person singular $-s$ in child L2 English. Language Learning, 62, 965-994.

Burgemeister, B., Hollander Blum, L., \& Lorge, I. (1972). Columbia Mental Maturity Scale. New York, NY: The Psychological Corporation.

Butt, J., \& Benjamin, D. (2004). A new reference grammar of modern Spanish (4th ed.). London, England: Hodder Education.

Bybee, J. (1995). Regular morphology and the lexicon. Language and Cognitive Processes, 10, 425-455.

Bybee, J. (2001). Phonology and language use. Cambridge, England: Cambridge University Press.

Bybee, J. (2007). Frequency of use and the organization of language. Oxford, England: Oxford University Press.

Bybee, J. (2008). Usage-based grammar and second language acquisition. In P. Robinson \& N. Ellis (Eds.), Handbook of cognitive linguistics and second language acquisition (pp. 216-236). New York, NY: Routledge.

Chatterjee, C., \& Hadi, A. S. (2006). Regression analysis by example. New York, NY: Wiley.

Conti-Ramsden, G. (2003). Processing and linguistic markers in young children with specific language impairment. Journal of Speech, Language, and Hearing Research, 46, 1029-1037.

Dunn, L., \& Dunn, L. (1997). The Peabody Picture Vocabulary Test (3rd ed.). Circle Pines, MN: AGS.

Edwards, J., \& Munson, B. (2009). Bases: Perception, production, and phonology. In R. Schwartz (Ed.), Handbook of child language disorders (pp. 216-231). New York, NY: Psychology Press.

Eyer, J., \& Leonard, L. (1994). Learning past tense morphology with specific language impairment: A case study. Child Language Teaching and Therapy, 10, 127-138.

Golberg, H., Paradis, J., \& Crago, M. (2008). Lexical acquisition over time in minority L1 children learning English as a L2. Applied Psycholinguistics, 29, 1-25.

Goldstein, B. (Ed.). (2004). Bilingual language development and disorder in Spanish-English speakers. Baltimore, MD: Brookes.

Gutiérrez-Clellen, V. (1996). Language diversity: Implications for assessment. In K. Cole, P. Dale, \& D. Thal (Eds.), Assessment of communication and language (pp. 29-46). Baltimore, MD: Brookes.

Jacobson, P. F., \& Schwartz, R. G. (2005). English past tense use in bilingual children with language impairment. American Journal of Speech-Language Pathology, 14, 313-323.

Johnson, B. W., \& Morris, S. R. (2007). Clinical implications of the effects of lexical aspect and phonology on children's 
production of the regular past tense. Child Language

Teaching and Therapy, 23, 287-306.

Kachru, Y. (2006). Hindi. Amsterdam, the Netherlands: Benjamins.

Leonard, L. (1998). Children with specific language impairment. Cambridge, MA: MIT Press.

Leonard, L., Bortolini, U., Caselli, M.-C., McGregor, K., \& Sabbadini, L. (1992). Morphological deficits in children with specific language impairment: The status of features in the underlying grammar. Language Acquisition, 2, 151-179.

Leonard, L., Ellis Weismer, S., Miller, C. A., Francis, D., Tomblin, B., \& Kail, R. (2007). Speed of processing, working memory, and language impairment in children. Journal of Speech, Language, and Hearing Research, 50, 408-428.

Lin, H. (2001). A grammar of Mandarin Chinese. Munich, Germany: Lincom Europa.

MacWhinney, B. (2008). Enriching CHILDES for morphosyntactic analysis. In H. Behrens (Ed.), Trends in corpus research: Finding structure in data (pp. 165-197). Amsterdam, the Netherlands: John Benjamins.

MacWhinney, B. (2010). The CHILDES Project: Tools for analyzing talk [Web manual]. Mahwah, NJ: Erlbaum. Retrieved from http://childes.psy.cmu.edu/manuals/clan.pdf

Marchman, V. A., \& Bates, E. (1994). Continuity in lexical and morphological development: A test of the critical mass hypothesis. Journal of Child Language, 12, 339-366.

Marchman, V. A., Wulfeck, B., \& Ellis Weismer, S. (1999). Morphological productivity in children with normal language and SLI: A study of the English past tense. Journal of Speech, Language, and Hearing Research, 42, 206-219.

Marinis, T., \& Chondrogianni, V. (2010). Production of tense marking in successive bilingual children: When do they converge with their monolingual peers? International Journal of Speech-Language Pathology, 12, 19-28.

Maslen, J. C., Theakston, A. L., Lieven, E. V., \& Tomasello, M. (2004). A dense corpus study of past tense and plural overregularization in English. Journal of Speech, Language, and Hearing Research, 47, 1319-1333.

Matthews, D. E., \& Theakston, A. (2006). Errors of omission in English-speaking children's production of plurals and the past tense: The effects of frequency, phonology and competition. Cognitive Science, 30, 1027-1052.

Matthews, S., \& Yip, V. (1991). Cantonese: A comprehensive grammar. London, England: Routledge.

Mercer, S. A. B. (1961). Introductory Assyrian grammar. New York, NY: F. Ungar.

Miller, C. A., Kail, R., Leonard, L. B., \& Tomblin, J. B. (2001). Speed of processing in children with specific language impairment. Journal of Speech, Language, and Hearing Research, 44, 416-433.

Norbury, C. F., Bishop, D. V. M., \& Briscoe, J. (2001). Production of English finite verb morphology: A comparison of SLI and mild-moderate hearing impairment. Journal of Speech, Language, and Hearing Research, 44, 165-178.

Oetting, J., Cleveland, L. H., \& Cope, R. (2008). Empirically derived combinations of tools and clinical cutoffs: An illustrative case with a sample of culturally/linguistically diverse children. Speech, Language, and Hearing Services in Schools, $39,44-53$.
Oetting, J., \& Horohov, J. (1997). Past tense marking by children with and without specific language impairment. Journal of Speech, Language, and Hearing Research, 40, 62-74.

Paradis, J. (2008). Tense as a clinical marker in English L2 acquisition with language delay/impairment. In B. Haznedar \& E. Gavruseva (Eds.), Current trends in child second language acquisition: A generative perspective (pp. 337-356). Amsterdam, the Netherlands: Benjamins.

Paradis, J. (2011). Individual differences in child English second language acquisition: Comparing child-internal and child-external factors. Linguistic Approaches to Bilingualism, 1, 213-237.

Paradis, J., Emmerzael, K., \& Sorenson Duncan, T. (2010). Assessment of English language learners: Using parent report on first language development. Journal of Communication Disorders, 43, 474-497.

Paradis, J., Genesee, F., \& Crago, M. (2011). Dual language development and disorders: A handbook on bilingualism and second language learning (2nd ed.). Baltimore, MD: Brookes.

Paradis, J., Nicoladis, E., Crago, M., \& Genesee, F. (2010). Bilingual children's acquisition of the past tense: A usagebased approach. Journal of Child Language, 37, 1-25.

Paradis, J., Rice, M., Crago, M., \& Marquis, J. (2008). The acquisition of tense in English: Distinguishing child second language from first language and specific language impairment. Applied Psycholinguistics, 29, 689-722.

Pinker, S., \& Ullman, M. (2002). The past and future of the past tense. Trends in Cognitive Science, 6, 456-463.

Pruitt, S. L., \& Oetting, J. B. (2009). Past tense marking by African American English-speaking children as a function of socioeconomic status. Journal of Speech, Language, and Hearing Research, 52, 2-15.

Redmond, S. M., \& Rice, M. L. (2001). Detection of irregular verb violations by children with SLI. Journal of Speech, Language, and Hearing Research, 44, 655-669.

Rice, M. L. (2003). A unified model of specific and general language delay: Grammatical tense as a clinical marker of unexpected variation. In Y. Levy \& J. Schaeffer (Eds.), Language competence across populations: Towards a definition of specific language impairment (pp. 63-94). Mahwah, NJ: Erlbaum.

Rice, M. L., \& Wexler, K. (2001). Test of Early Grammatical Impairment. New York, NY: The Psychological Corporation.

Rice, M. L., Wexler, K., \& Cleave, P. (1995). Specific language impairment as a period of extended optional infinitive. Journal of Speech, Language, and Hearing Research, 38, 850-863.

Rice, M. L., Wexler, K., \& Hershberger, S. (1998). Tense over time: The longitudinal course of tense acquisition in children with specific language impairment. Journal of Speech, Language, and Hearing Research, 41, 1412-1431.

Rice, M. L., Wexler, K., Marquis, J., \& Hershberger, S. (2000). Acquisition of irregular past tense by children with specific language impairment. Journal of Speech, Language, and Hearing Research, 43, 1126-1145.

Saeed, J. I. (1993). Somali reference grammar. Kensington, MD: Dunwoody Press.

Schmidt, R. L. (1999). Urdu: An essential grammar. London, England: Routledge. 


\section{Complimentary Author PDF: Not for Broad Dissemination}

Thompson, L. C. (1987). A Vietnamese reference grammar. Honolulu: University of Hawaii Press.

Van der Lely, H., \& Ullman, M. (2001). Past tense morphology in specifically language impaired and normally developing children. Language and Cognitive Processes, 16, 177-217.

Windsor, J., \& Huang, M. (1999). Testing the generalized slowing hypothesis in SLI. Journal of Speech, Language, and Hearing Research, 42, 1205-1218.

Zdorenko, T., \& Paradis, J. (2008). The acquisition of articles in child second language English: Fluctuation, transfer or both? Second Language Research, 24, 227-250.
Zdorenko, T., \& Paradis, J. (2011). Articles in child L2 English: When L1 and L2 acquisition meet at the interface. First Language, 32, 38-62. doi:10.1177/0142723710396797

Zdorenko, T., \& Paradis, J. (2012). Articles in child L2 English: When L1 and L2 acquisition meet at the interface. First Language, 32, 1-2, 38-62.

Appendix. TEGI verbs and verbs used by the English L2 children.

\begin{tabular}{|c|c|c|}
\hline Verb type & $\begin{array}{c}\text { TEGI verbs } \\
\text { (Rice \& Wexler, 2001) }\end{array}$ & Verbs used by the children \\
\hline Regular & $\begin{array}{l}\text { brush, clean, climb, } \\
\text { jump, kick, lift, paint, } \\
\text { pick, plant, tie }\end{array}$ & $\begin{array}{l}\text { brush, carry, chew, clean, climb, comb, fence, } \\
\text { finish, fix, grab, help, hug, jump, kick, lift, open, } \\
\text { paint, pick, plant, shovel, smell, splash, start, } \\
\text { stop, tie, try, walk, want }\end{array}$ \\
\hline Irregular & $\begin{array}{l}\text { blow, catch, dig, eat, } \\
\text { give, make, ride, write }\end{array}$ & $\begin{array}{l}\text { blow, build, catch, choose, cut, dig, draw, eat, fly, } \\
\text { get, give, go, grow, hang, make, ride, run, say, } \\
\text { sit, stand, take, tell, throw, write }\end{array}$ \\
\hline
\end{tabular}

Note. TEGI = Test of Early Grammatical Impairment; $L 2$ = second language. 